\title{
Time series analysis of plasma LH and FSH concentrations as a method of assessing episodic secretion
}

\author{
B. J. McLeod and J. Craigon* \\ A.F.R.C. Research Group on Hormones and Farm Animal Reproduction and *Biometry Unit, \\ Department of Physiology and Environmental Science, University of Nottingham, School of \\ Agriculture, Sutton Bonington, Loughborough, Leics LE12 5RD, U.K.
}

\begin{abstract}
Summary. Time series analysis was used to detect LH and FSH episodes in untreated seasonally anoestrous ewes and prepubertal heifers, and in these animals when treated with low doses of GnRH. For comparison, these profiles were also assessed for episodic secretion by subjective, visual appraisal methods and by cycle detection-an objective threshold method. In untreated animals, time series analysis detected recurring events in the LH and FSH profiles, the period lengths of which varied between individual animals. When GnRH was injected at 2-h intervals, cycles in $\mathbf{L H}$ secretion with period lengths of $120 \mathrm{~min}$ were recorded in all animals, of $60 \mathrm{~min}$ in all ewes and $11 / 12$ heifers, and of $40.5 \mathrm{~min}$ in $22 / 24$ ewes and 10/12 heifers. The cycles with period lengths of 60 and $40.5 \mathrm{~min}$ are probably artefacts of this method of analysis. No consistent cycles in FSH release were detected in GnRH-injected anoestrous ewes, but 120-min cycles were recorded in 8/12 GnRH-injected heifers. When GnRH was administered to seasonally anoestrous ewes by continuous infusion, recurring cycles in both $\mathrm{LH}$ and FSH secretion were evident. However, there was no consistency in their period lengths and the mean number and frequency of cycles were similar to pretreatment values. The number of episodes detected by visual appraisal was influenced by the choice of episode definition. Both methods identified LH, but not FSH, episodes in response to each injection in all GnRH-injected animals. Cycle detection, which does not identify individual episodes, recorded LH and FSH episode frequencies similar to those detected by the more stringent method of visual appraisal.

Time series analysis detected an FSH response to GnRH injections in prepubertal heifers that was not identified by the other methods of analysis. However, because of the asymmetric nature of LH episodes, it also detected cycles in LH profiles that were probably spurious. Subjective decisions influenced the frequencies of LH and FSH episodes recorded by visual appraisal, and the variation in episode amplitude in these profiles made cycle detection inappropriate. Each of these methods can contribute to the interpretation of hormone profiles, but their constraints and limitations must be recognized.
\end{abstract}

\section{Introduction}

Plasma concentrations of LH and FSH fluctuate in an episodic manner and changes in reproductive function are often associated with changes in the frequency and amplitude of episodes. In the ewe and the cow, an increase in LH episode frequency precedes the onset of puberty (Ryan \& Foster, 1980; Schams, Schallenberger, Gombe \& Karg, 1981), the resumption of ovarian cyclicity post partum (Lamming, Wathes \& Peters, 1981) and the final stages of follicular growth before ovulation (Baird, 1978; Rahe, Owens, Fleeger, Newton \& Harms, 1980) Similar 
changes in episodic patterns have been reported for FSH (Walters, Schams \& Schallenberger, 1984; Walters \& Schallenberger, 1984). Quite often, however, episodic hormone secretion is difficult to interpret because both the definition and identification of episodes are confounded by differences in episode frequency and amplitude and by changes in baseline concentrations of the hormone. For example, high-amplitude, low-frequency LH episodes can easily be identified in anoestrous ewes in which baseline LH concentrations are low, but it becomes increasingly difficult to identify high-frequency, low-amplitude episodes during the follicular phase of the oestrous cycle when baseline concentrations are constantly increasing (McLeod, Haresign \& Lamming, 1983).

Various analytical techniques have been used in attempts to assess episodic secretion: these include subjective methods involving visual inspection of hormone profiles, and numerous objective methods in which any increase above a predetermined threshold is deemed to be an episode. Methods of time series analysis have been used to analyse hormonal patterns in man (Vagnucci, Wong \& Liu, 1974; Ellis, Randall, Becket \& Dudley, 1978), rats (Wilson \& Morgan, 1979) and sheep (Almeida \& Lincoln, 1982; Howles, Craigon, \& Haynes, 1982) and these have revealed regular periodicities in secretion.

In the present paper, we report the application of time series analysis to episodic LH and FSH release in the hormone profiles of acyclic animals in which episodes occurred irregularly and infrequently, and in these animals when exogenous GnRH was administered. GnRH was given either as a series of injections in an attempt to impose a regular pattern of episodic secretion, or it was infused continuously to elevate baseline concentrations. For comparison, these hormone profiles were also analysed for episodic secretion by a subjective, visual appraisal method and by an objective threshold method.

\section{Materials and Methods}

\section{Animals}

Seasonally anoestrous Clun Forest ewes $(N=34$, mean \pm s.e.m. liveweight $61.9 \pm 1.4 \mathrm{~kg})$ were used between late May and early August, a period extending from early to late anoestrus in this breed. In addition, 12 prepubertal Hereford $\times$ Friesian heifers were treated at 5 months of age. Animals of this breed typically attain puberty between 9 and 15 months of age.

\section{Treatment and blood sampling}

Anoestrous ewes. The experimental protocol has been described in detail elsewhere (McLeod et al., 1982b, 1983). Briefly, 24 ewes were injected i.v. with $75,125,250$ or $500 \mathrm{ng}$ GnRH at 2-h intervals for $48 \mathrm{~h}$, and 10 ewes received 125 or $250 \mathrm{ng} \mathrm{GnRH} / \mathrm{h}$ as a continuous i.v. infusion for $48 \mathrm{~h}$. Blood samples for LH and FSH determination were collected at 15-min intervals from all GnRHtreated ewes from $12 \mathrm{~h}$ before the start until $12 \mathrm{~h}$ after the end of the treatment period.

Prepubertal heifers. The experimental protocol has been described by McLeod, Peters, Haresign \& Lamming (1985). All 12 animals were injected i.v. with $2.0 \mu \mathrm{g} \mathrm{GnRH}$ at 2-h intervals for $72 \mathrm{~h}$. Blood samples were collected at 15 -min intervals from $24 \mathrm{~h}$ before the start until $8 \mathrm{~h}$ after the end of the GnRH treatment period.

Hormone analysis. The radioimmunoassay methods employed and their reliability criteria are listed in Table 1.

\section{Analysis of data}

For each animal, hormone profiles were assessed for episodic secretion patterns in two discrete sections: firstly, the $12 \mathrm{~h}$ (sheep) or $24 \mathrm{~h}$ (heifers) pretreatment period and, secondly, the period of GnRH treatment, i.e. from the start of treatment until the onset of the preovulatory surge, or until 
Table 1. Methods and reliability criteria of radioimmunoassay procedures

\begin{tabular}{llccc}
\hline & & \multirow{2}{*}{$\begin{array}{c}\text { Limits of } \\
\text { sensitivity } \\
\text { Hormone }\end{array}$} & \multicolumn{1}{c}{ Method } & \multicolumn{2}{c}{ Coefficients of Variation } \\
\cline { 4 - 6 } & $(\mathrm{ng} / \mathrm{ml})$ & Intra-assay & Inter-assay \\
\hline Ovine LH & Foster \& Crighton (1974) & 0.3 & 6.7 & 9.6 \\
& McLeod et al. (1982a) & & & \\
Ovine FSH & Webb et al. (1980) & 9.2 & 9.7 & 13.2 \\
Bovine LH & Webb et al. (1977) & 0.4 & 6.3 & 11.9 \\
Bovine FSH & Webb et al. (1980) & 9.7 & 8.2 & 12.8 \\
\hline
\end{tabular}

the end of the treatment period in those animals in which a surge was not recorded. The definitions used to characterize a preovulatory LH surge were those of McLeod \& Haresign (1984) and McLeod et al. (1985). Hormone levels were analysed by analysis of variance. Except when the same frequency estimate was produced for all animals within a group, differences in episode frequency were analysed assuming Poisson errors. Episodic LH and FSH secretion was assessed by visual appraisal, cycle detection and time series analysis, in the following manner.

Visual appraisal. Profiles were scanned for episodic secretion patterns using two separate sets of criteria for defining episodes. The more stringent definition (Definition A) was designed to identify episodes similar to those occurring in the acyclic animal when baseline hormone concentrations were low (see Text-figs 2 \& 3). An elevation in plasma hormone concentrations was deemed to be an episode if, (i) the peak occurred within 3 samples of the previous nadir, (ii) the increase was at least 4 times greater than the coefficient of variation of duplicate pairs of the assay, (iii) the peak concentration exceeded $1.0 \mathrm{ng} / \mathrm{ml}(\mathrm{LH})$ or $10 \mathrm{ng} / \mathrm{ml}$ plasma (FSH) and (iv) that there were at least 2 sample points between the peak and the subsequent nadir. In contrast, the second definition (Definition B) recognized as an episode any increase in plasma concentrations which (i) represented an increase greater than $0.5(\mathrm{LH})$ or $5.0(\mathrm{FSH}) \mathrm{ng} / \mathrm{ml}$ plasma and (ii) which included at least 2 sample points between the peak and the subsequent nadir.

Cycle detection. The modified threshold method of Clifton \& Steiner (1983), in which an adaptive threshold is adjusted to equalize the probability of rejecting true episodes with the probability of detecting false episodes, was used. An iterative, computerized procedure scans the data identifying sequential increases and decreases greater than an initial, preset threshold value, and defines as a complete cycle (an episode), two increases greater than threshold separated by a decrease which is also greater than threshold. Initially, the threshold is set at 2.7 times the standard deviation of duplicate pairs of the assay. The data are scanned, then the threshold is adjusted using an empirically derived formula, and the data are scanned again. This process is repeated until the number of cycles detected reaches a stable value.

Time series analysis. The LH and FSH measurements were examined for periodicity by autocorrelation and spectral analysis techniques. The methods employed were those of Howles $e t$ al. (1982).

For autocorrelation, sequences of samples are shifted along the profile by fixed period lengths, to be correlated with later sequences. Large positive correlations at particular period lengths indicate cyclicity with those periods. Their detection can be aided by plotting the autocorrelations against their associated period lengths (a correlogram).

Spectral analysis describes the hormone profile as the sum of a number of sine waves, each having its own frequency, phase and amplitude. The proportion of the variance in the original data that can be attributed to a particular wave, is the spectral density estimate for that wave's frequency. The production of a spectrogram, the plot of spectral density estimates against frequency for a range of frequencies, can often clarify features which are obscure in the correlogram. Spectral density estimates were determined by Fourier transformation of the autocorrelations, and smoothed using the Parzen smoothing window. This combination enables 
confidence limits to be placed on the estimates and for peaks in the spectrogram to be tested by the method of Rahe et al. (1980). This test is based upon comparison of the smoothed spectra with the unsmoothed spectral density estimates. Although the choice of which of the commoner smoothing windows used makes little difference to the final spectrogram (Jenkins \& Watts, 1968), the degree of smoothing affects which peaks are considered spurious. Therefore, the transformation was calculated at 3 smoothing bandwidths and the spectrogram for consistent peaks. Such peaks were then tested for significance.

A representative spectrogram is shown in Text-fig. 1 with the 4 curves representing 3 smoothed spectra and the unsmoothed spectra. The area under each curve represents the total variation in hormone levels, hence a peak at any frequency indicates that a cycle at that frequency would account for more of the variation than cycles at adjacent frequencies. Frequencies which showed consistent peaks at each of the three degrees of smoothing used, were considered to indicate cycles in the data. The confidence limits provide a guide as to how much the lines need to fluctuate to produce a detectable peak, and the bandwidths indicate the distance by which adjacent peaks must be separated before they can be considered as representing different cycles.

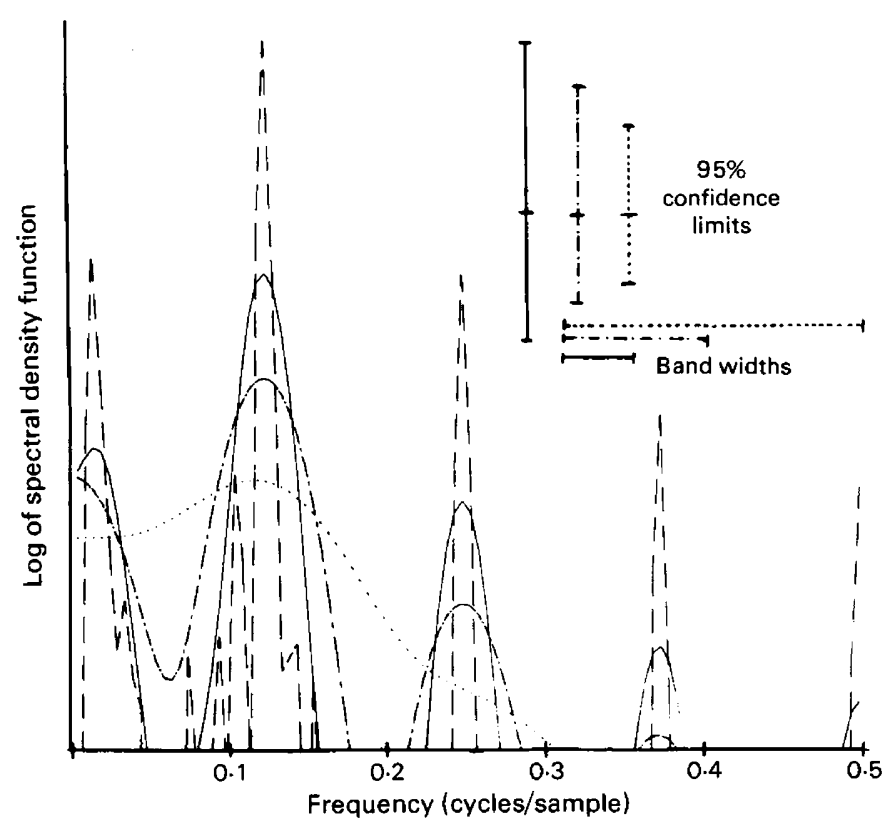

Text-fig. 1. Spectrogram obtained from time series analysis of the plasma LH profile of a seasonally anoestrous ewe injected with GnRH at 2 -h intervals. The unsmoothed line is represented as ---, and the 3 smoothed lines with their respective confidence limits as $-\cdot-\cdot$, and $\cdots \cdots \cdot$ with increasing degress of smoothing.

\section{Results}

\section{Plasma LH concentrations}

In seasonally anoestrous ewes, treatment with GnRH resulted in a significant increase $(P<$ 0.001 ) in plasma $\mathrm{LH}$ concentrations from pretreatment levels of $1.1 \pm 0.1 \mathrm{ng} / \mathrm{ml}$, to mean concentrations of $3.8 \pm 0.8$ and $8.4 \pm 1.6 \mathrm{ng} / \mathrm{ml}$ in animals subjected to repeated injections and continuous infusion respectively. A preovulatory-type surge was recorded in all GnRH-treated 

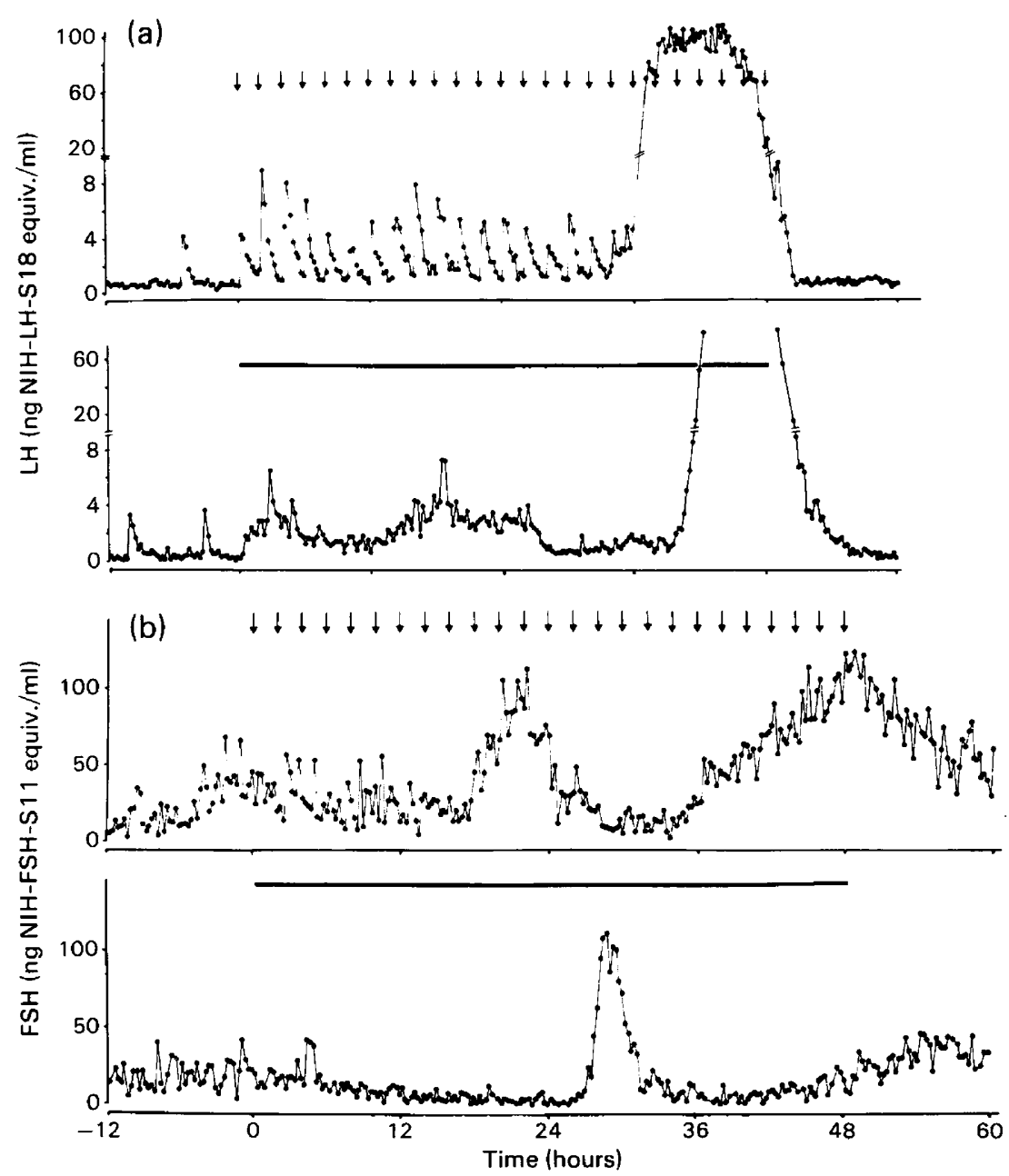

Text-fig. 2. Plasma concentrations of (a) LH and (b) FSH in 4 seasonally anoestrous ewes treated with repeated i.v. injections or continuous i.v. infusion of low doses of GnRH. The times of GnRH injection are indicated by the arrows and the period of GnRH infusion by the solid bars. Blood samples were collected at 15 -min intervals.

ewes and this occurred at a mean time of $29.3 \pm 1.9 \mathrm{~h}$ (repeated injections) and $35.2 \pm 2.0 \mathrm{~h}$ (continuous infusion) after the start of treatment.

In prepubertal heifers, mean LH concentrations were $1.4 \pm 0.2 \mathrm{ng} / \mathrm{ml}$ over the $24-\mathrm{h}$ pretreatment period, and increased to $3 \cdot 0 \pm 0 \cdot 3 \mathrm{ng} / \mathrm{ml}$ over the period of $\mathrm{GnRH}$ injections. Only $9 / 12$ heifers subsequently produced a preovulatory LH surge, and this occurred at a mean time of $41 \cdot 2 \pm 4 \cdot 3 \mathrm{~h}$ after the start of treatment. Individual LH profiles are shown for 2 ewes in Text-fig. 2(a) and for 2 heifers in Text-fig. 3(a).

\section{Episodic $L H$ release}

When the data were assessed visually for $\mathrm{LH}$ episodes, means of 1.9 and 3.2 episodes $/ 12 \mathrm{~h}$ were recorded in anoestrous ewes, when using Definitions A and B respectively. Frequencies of $2 \cdot 1$ episodes/12 h (Definition A) and 2.2 episodes/12 h (Definition B) were monitored over the 

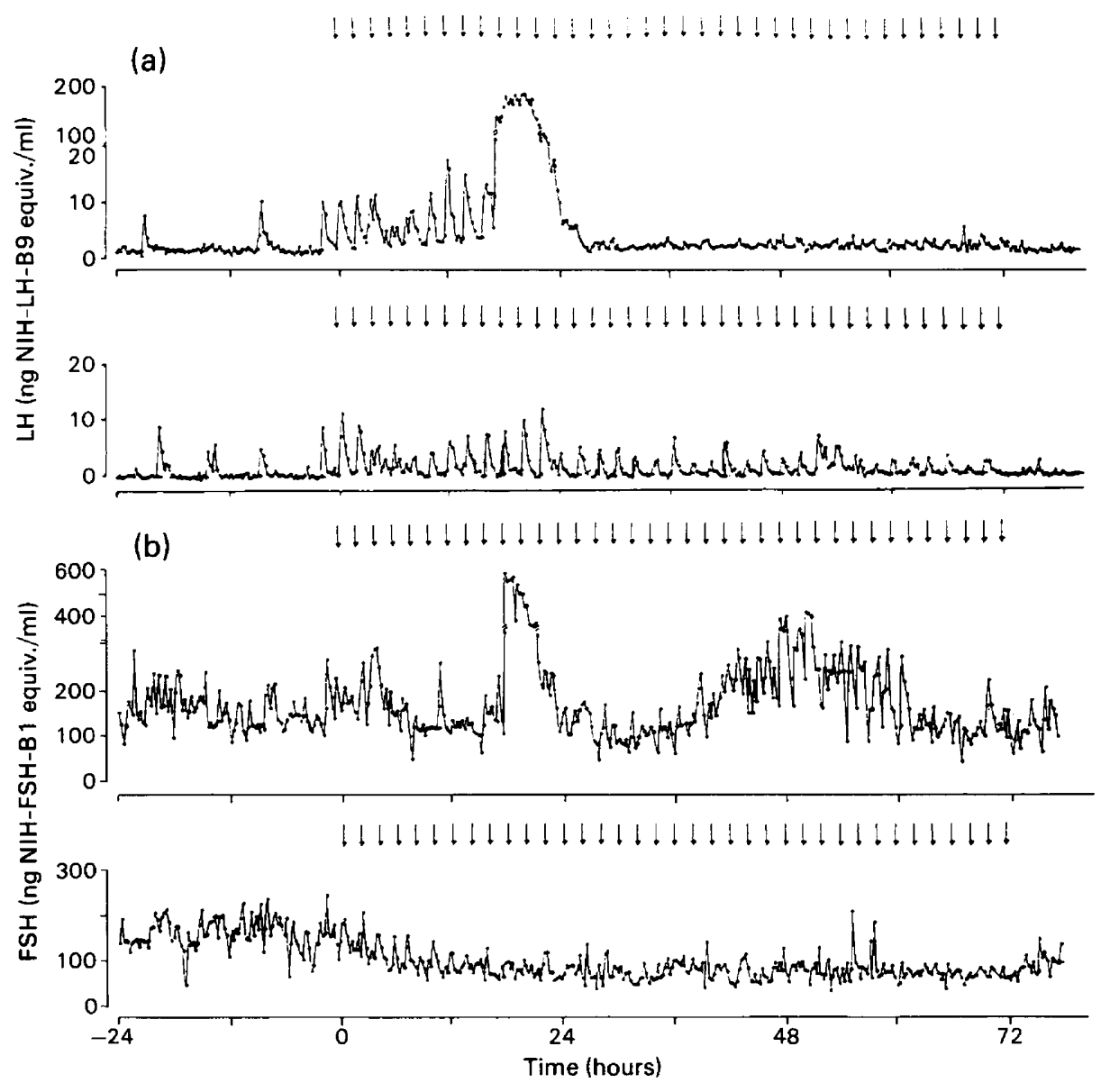

Text-fig. 3. Plasma concentrations of (a) LH and (b) FSH in prepubertal heifers treated with repeated injections of $2 \mu \mathrm{g} \mathrm{GnRH}$. The times of $\mathrm{GnRH}$ injections are indicated by the arrows. Blood samples were collected at 15 -min intervals.

pretreatment period in prepubertal heifers. Irrespective of the definition employed, the frequency of LH episodes was significantly increased $(P<0.001)$ by treatment with GnRH, whether administered by repeated injection or by continuous infusion. In animals treated with $\mathrm{GnRH}$ at $2-\mathrm{h}$ intervals, both definitions detected an LH episode in response to each injection.

The mean frequencies with which LH episodes were recorded by cycle detection were similar to those detected by the more stringent method (Definition A) of visual appraisal (see Table 2). Although cycle detection recorded a frequency of $\mathrm{LH}$ episodes compatible with a regular 2-h pattern of LH episodes in 9/24 anoestrous ewes and 5/12 prepubertal heifers injected with GnRH at 2-h intervals, this method of analysis does not identify individual episodes. Therefore, it was not possible to determine whether LH episodes were associated with GnRH injections.

The mean frequencies of $\mathrm{LH}$ episodes detected by the two methods of visual appraisal and for cycle detection, and their distributions, are shown in Table 2 and Text-fig. 4 respectively. Over the pretreatment period, visual appraisal using Definition B detected a significantly higher $(P<0.01)$ mean frequency of LH episodes than did the other two methods. There were no significant differences between these three methods of analysis, in the mean frequencies of LH episodes detected in ewes or heifers over the periods of GnRH treatment. 
Table 2. Mean frequencies (episodes/12 h) of LH and FSH episodes* in seasonally anoestrous ewes and prepubertal heifers treated with repeated injections or continuous infusion of $\mathrm{GnRH}$, as detected by visual appraisal or cycle detection

\begin{tabular}{|c|c|c|c|c|c|}
\hline Hormone & Animals & Method of analysis & $\begin{array}{l}\text { Pretreatment } \\
\text { period }\end{array}$ & $\begin{array}{l}\text { Repeated } \\
\text { injections } \\
\text { of GnRH }\end{array}$ & $\begin{array}{l}\text { Continuous } \\
\text { infusion } \\
\text { of GnRH }\end{array}$ \\
\hline \multirow[t]{6}{*}{ LH } & Anoestrous ewes & Visual appraisal (Definition A) & $1.9(1-6)$ & $6.0(6)$ & $6 \cdot 8(5-8)$ \\
\hline & & Visual appraisal (Definition B) & $3 \cdot 2(1-7)$ & $6.9(6-8)$ & $8 \cdot 1(7-9)$ \\
\hline & & Cycle detection & $2 \cdot 1(1-5)$ & $5 \cdot 5(4-7)$ & $6 \cdot 3(5-8)$ \\
\hline & Prepubertal heifers & Visual appraisal (Definition A) & $2 \cdot 1(1-3)$ & $6.0(6)$ & - \\
\hline & & Visual appraisal (Definition B) & $2 \cdot 2(1-5)$ & $6 \cdot 5(6-8)$ & - \\
\hline & & Cycle detection & $2 \cdot 3(1-3)$ & $5 \cdot 7(5-7)$ & - \\
\hline \multirow{6}{*}{ FSH } & Anoestrous ewes & Visual appraisal (Definition A) & $3 \cdot 8(1-6)$ & $5 \cdot 2(1-9)$ & $5 \cdot 2(3-7)$ \\
\hline & & Visual appraisal (Definition B) & $4 \cdot 6(1-8)$ & $7.0(4-10)$ & $6 \cdot 5(4-8)$ \\
\hline & & Cycle detection & $4 \cdot 4(2-7)$ & $4 \cdot 3(2-6)$ & $4 \cdot 2(3-6)$ \\
\hline & Prepubertal heifers & Visual appraisal (Definition A) & $4 \cdot 6(3-7)$ & $5 \cdot 4(4-8)$ & - \\
\hline & & Visual appraisal (Definition B) & $4 \cdot 8(3-7)$ & $6 \cdot 2(4-8)$ & - \\
\hline & & Cycle detection & $4 \cdot 2(3-5)$ & $4 \cdot 7(3-6)$ & - \\
\hline
\end{tabular}

* Numbers in parentheses indicate the range of frequencies detected within each group.

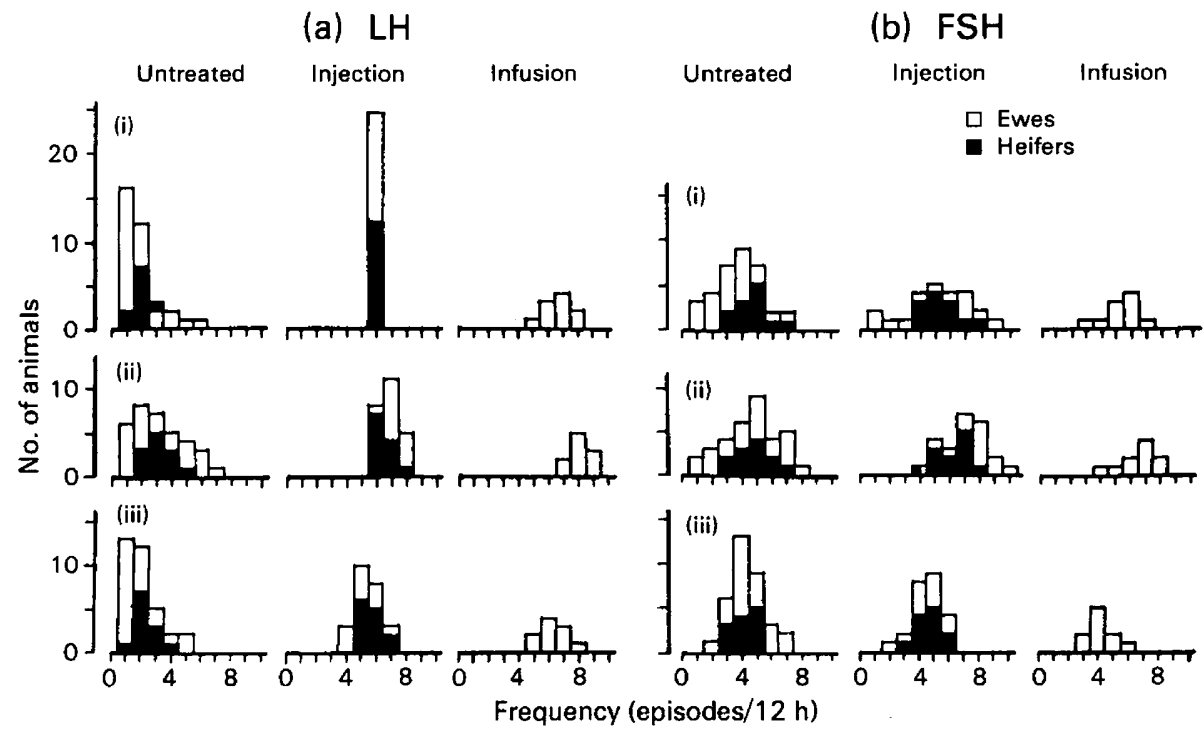

Text-fig. 4. The frequency distribution of (a) LH episodes and (b) FSH episodes as detected by visual appraisal using (i) Definition A or (ii) Definition B or (iii) cycle detection. The hormone profiles were from untreated animals ( 34 anoestrous ewes, 12 prepubertal heifers) or from animals given i.v. injections at 2 -h intervals ( 24 anoestrous ewes, 12 prepubertal heifers), or continuous i.v. (10 anoestrous ewes) of GnRH.

When time series analysis was applied to the pretreatment $\mathrm{LH}$ profiles, recurring events in secretion were detected in all the seasonally anoestrous ewes. The period lengths corresponding to the frequencies at which these peaks on the spectrogram were detected varied between individual animals and ranged from 30 to $1500 \mathrm{~min}$. The period lengths detected over the range 30 to $370 \mathrm{~min}$ are shown in Text-fig. 5(i). Time series analysis of that section of the profile extending from the 
(i)
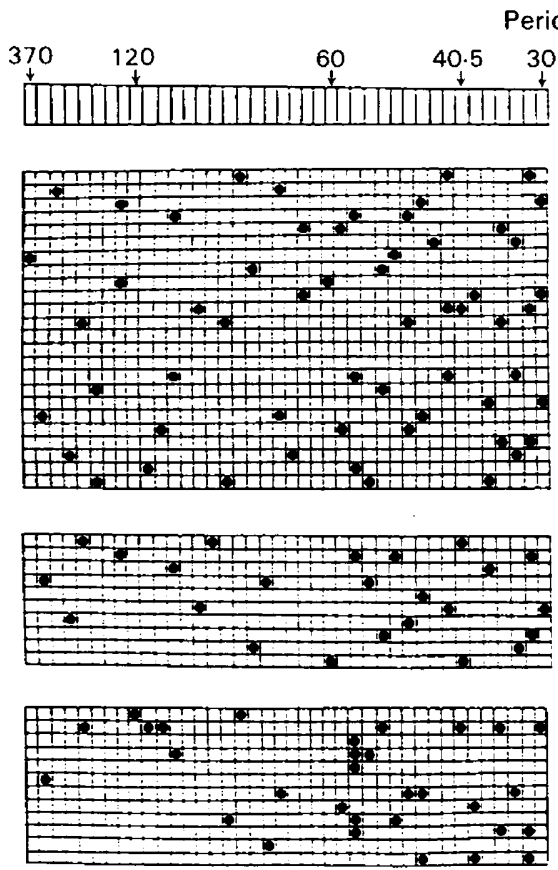

(ii)

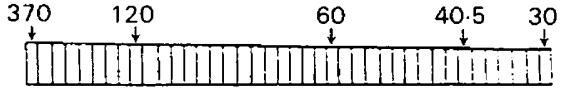

(a)

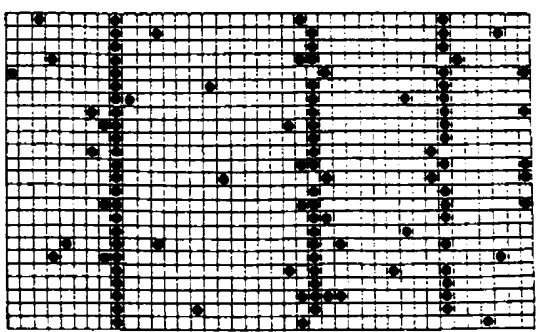

(b)

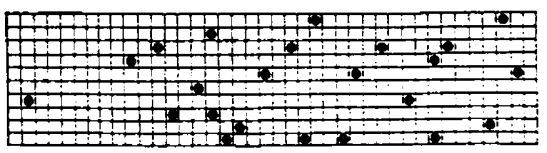

(c)

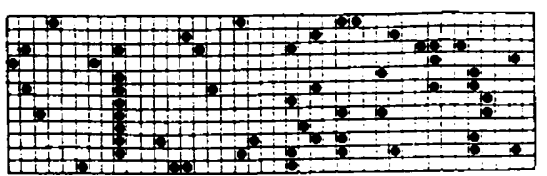

Text-fig. 5. The period lengths ( $\mathrm{min}$ ) of recurring cycles detected by time series analysis in hormone profiles before (i) and during (ii) treatment with low doses of GnRH. Cycles were monitored in LH profiles of seasonally anoestrous ewes treated with (a) repeated i.v. injections or (b) continuous i.v. infusion and in (c) FSH profiles of prepubertal heifers treated with repeated i.v. injections. Within a panel, each row shows the cycles detected for an individual animal. Adjacent rows represent the same animal before and during treatment.

start of GnRH treatment until the onset of the preovulatory LH surge also revealed recurring events in secretion. Although variation in cycle frequency was again apparent between animals, there were three periodicities which occurred consistently in ewes injected with GnRH at 2-h intervals, irrespective of the dose administered. Significant peaks in the spectrogram were detected in all these animals at frequencies corresponding to period lengths of about $120 \mathrm{~min}$ and $60 \mathrm{~min}$, and, in $22 / 24$ animals, to a period length of $40.5 \mathrm{~min}$. In contrast, in the animals infused with GnRH, no consistency of period lengths was apparent (see Text-fig. 5ii).

Similarly, recurring events in LH secretion, in which the frequency varied between animals, were apparent in prepubertal heifers whether untreated or injected with GnRH. In addition, the same three periodicities, i.e. 120,60 and $45.5 \mathrm{~min}$, were also detected in $12 / 12,11 / 12$ and $10 / 12$ heifers over the period when GnRH was injected at 2-h intervals.

\section{Plasma FSH concentrations}

In seasonally anoestrous ewes, mean FSH concentrations were $21.4 \pm 1.9 \mathrm{ng} / \mathrm{ml}$ over the pretreatment period. In most animals treatment with $\mathrm{GnRH}$, whether by repeated injections or continuous infusion, resulted in a suppression of FSH release. Mean plasma levels were $16.6 \pm 1.6$ and $16.5 \pm 1.9 \mathrm{ng} / \mathrm{ml}$ over the period of $\mathrm{GnRH}$ treatment in animals treated by injection and infusion respectively. A preovulatory FSH surge occurred coincident with the LH surge in all animals. In prepubertal heifers, mean plasma FSH concentrations were $64 \cdot 1 \pm 15 \cdot 5 \mathrm{ng} / \mathrm{ml}$ over the 
pretreatment period and $49 \cdot 2 \pm 11 \cdot 2 \mathrm{ng} / \mathrm{ml}$ over the period of GnRH treatment. A preovulatory FSH surge was recorded in $8 / 9$ of the animals in which an $\mathrm{LH}$ surge was monitored. Individual FSH profiles for 2 ewes and for 2 heifers are shown in Text-figs 2(b) and 3(b), respectively.

\section{Episodic FSH release}

The mean frequencies of FSH episodes as detected by visual appraisal and by cycle detection are shown in Table 2 and the distribution of their frequencies in Text-fig. 4(b). Unlike the pattern observed for LH secretion, a regular 2-h cycle in episodic FSH release was not visually apparent in any of the animals that received 2-h injections of GnRH (see Text-figs 2 \& 3). In the GnRHinjected and GnRH-infused anoestrous ewes, visual appraisal using Definition B detected a significantly higher $(P<0.05)$ mean frequency of FSH episodes than did the other two methods (see Table 2). There were no significant differences between the mean frequencies of FSH episodes detected by each of the three methods in untreated ewes, or in treated and untreated heifers.

Time series analysis of the pretreatment FSH profiles of seasonally anoestrous ewes detected recurring events in secretion with period lengths that ranged from 30 to $1500 \mathrm{~min}$. Such cycles in FSH secretion were also observed over the period of GnRH administration, but there were no consistent patterns in period lengths (Text-fig. 5b). Cycles in FSH secretion, which varied in frequency between animals, were also detected in prepubertal heifers. However, in contrast to the pattern observed in anoestrous ewes, FSH cycles corresponding to a period length of 120 min were detected in 8/12 heifers injected with $\mathrm{GnRH}$ at 2-h intervals. This included 6/8 animals which produced a preovulatory FSH surge, and $2 / 4$ animals which did not. The period lengths of FSH cycles detected in individual heifers are indicated in Text-fig. 5(c).

\section{Discussion}

The interpretation of episodic patterns of gonadotrophin release is often difficult, due to problems in the identification and definition of individual episodes. This is clearly demonstrated by the widely different results obtained using each of the two methods of visual appraisal. For example, even when the mean frequencies of episodes detected by each definition were similar, the range of their distributions was often very different (see Table 2 and Text-fig. 4). Cycle detection produced yet another range of distributions, partly due to the requirement of this method for two increases in hormone concentration to describe one complete cycle, and so the number of episodes/profile should be one greater than the number of cycles/profile. In addition, cycle detection requires that episodes be of equal amplitude to delimit a cycle, therefore the occurrence of episodes of irregular amplitude can result in an underestimate of episode frequency (Clifton \& Steiner, 1983).

Time series analysis provides an objective method of detecting regular cycles or rhythms in hormone secretion. The fact that hormone profiles can be described by a few regular cycles of different periodicities and amplitudes is illustrated for one ewe injected with $\mathrm{GnRH}$, and for one ewe infused with GnRH in Text-figs 6(a) and 6(b). The lower four lines in each figure are sinusoids, the frequencies of which are the harmonics of the fundamental frequencies nearest to the four dominant periodicities detected in the LH profile. When combined, these four curves produce a simulated LH pattern which, despite the approximations imposed, explains most of the variation in the original profile. In each figure, the recombined curve and the original LH profile are plotted for comparison as the two upper lines.

The detection of recurring cycles in hormone secretion in untreated animals, and in those treated with the saline vehicle alone, would be expected with this form of analysis (Vagnucci et al., 1974). Furthermore, the lack of any consistent patterns between animals would be predicted in view of the irregular and asynchronous nature of episodic gonadotrophin secretion. In spite of a significant elevation $(P<0.001)$ in mean LH concentrations and a significant depression $(P<$ 
(i)

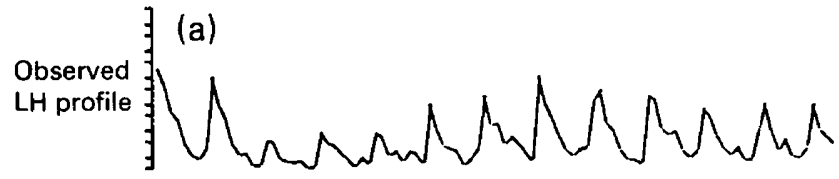

(ii)

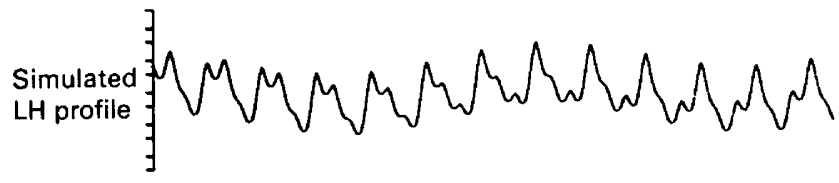

(iii)

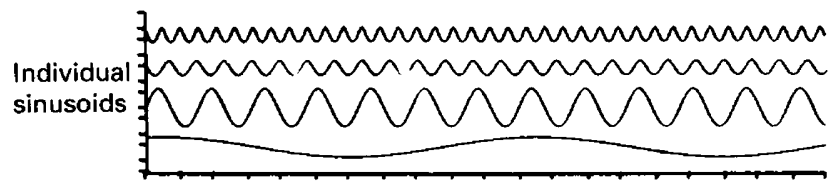

(i)

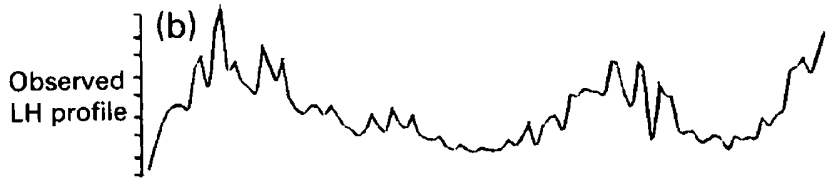

(ii)

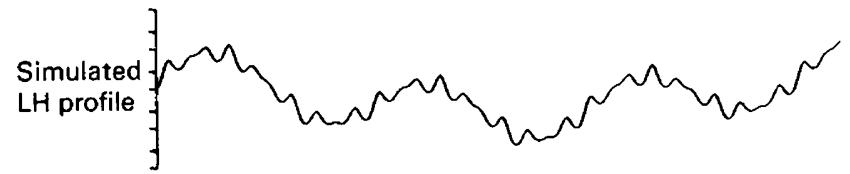

(iii) Individual sinusoids

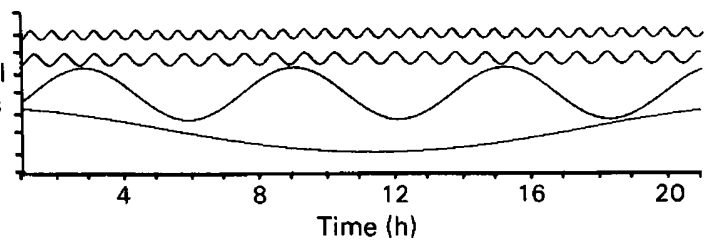

Text-fig. 6. Comparison of (i) observed and (ii) simulated LH profiles of (a) one ewe injected at 2-h intervals and (b) one ewe infused continuously with $\mathrm{GnRH}$, together with (iii) the four constituent sinosoids which were summed to produce the simulated profile.

0.01 ) in mean FSH concentrations in animals subjected to continuous infusion of GnRH, similar numbers and frequencies of cycles were detected before and during treatment. In contrast, 2-h injections of $\mathrm{GnRH}$ resulted in a high degree of synchronization of cycle frequency in the $\mathrm{LH}$ profiles of anoestrous ewes and prepubertal heifers. The 120-min cycle in LH secretion is clearly a direct response to each GnRH injection and these were also obvious by simple inspection of the hormone profiles. However, the physiological significance, if any, of the cycles with a periodicity of 60 and $40.5 \mathrm{~min}$ which were also detected in these animals is unclear. These cycles may reflect inherent rhythms in $\mathrm{LH}$ release that become detectable only when $\mathrm{LH}$ episodes are artificially synchronized. In support of this suggestion is evidence that such rhythms in LH secretion occur in a number of species. For example, when the feedback influences of steroid hormones are removed by gonadectomy, the interval between LH episodes has been reported as 20-25 min in the rat (Gay \& Sheth, 1972), 40-60 min in the cow (Beck \& Convey, 1976; Rahe, Fleeger \& Harms, 1982), 60 min in the rhesus monkey (Dierschke, Bhattacharya, Atkinson \& Knobil, 1970) and 40-60 min in the ewe and the prepubertal lamb (Roche, Foster, Karsch \& Dziuk, 1970; Butler, Malven, Willet \& Bolt, 1972; Foster, Jaffe \& Niswender, 1975; Goodman \& Karsch, 1980). Furthermore, the endogenous GnRH output is also pulsatile with an interval between pulses of about $39 \mathrm{~min}$ in the ovariectomized ewe (Clarke \& Cummins, 1982; Levine, Pau, Ramirez \& Jackson, 1982). It is more 
probable, however, that the 60 - and $40 \cdot 5-\mathrm{min}$ cycles do not reflect physiological events, but are merely artefacts of this method of analysis. Chatfield (1979) points out that spectra containing a large peak at frequency $\Omega$, may contain related peaks at $2 \Omega, 3 \Omega$ etc., and that these harmonics generally result from the non-sinusoidal character of the main cyclical component. By focussing attention on the time domain (i.e. period length) as we have done in this analysis, instead of the frequency domain (cycle/unit time), an important feature of the spectra for the injected animals is easily overlooked, because although the three consistent period lengths of 120,60 and $40.5 \mathrm{~min}$ are not integer multiples of each other, their corresponding frequencies of $0.125,0.250$ and 0.375 cycles/sample are such multiples and so the $60-$ and $40 \cdot 5-\mathrm{min}$ cycles are simple harmonics of the main 120 min cycle. The asymmetric (sawtooth) shape of LH episodes (see Text-figs 2 \& 3 ) may therefore provide an explanation for the presence of frequencies of 0.250 and 0.375 cycles/sample in those spectra that exhibit large peaks at frequencies of 0.125 cycle/sample (i.e. 120 -min cycles).

The absence of 120-min cycles in FSH secretion in ewes injected with GnRH is probably indicative of the lack of a consistent pituitary response in these animals rather than of a shortcoming of time series analysis, because cycles of this period length were detected in $8 / 12 \mathrm{GnRH}$ injected heifers. Reports that suggest that the prepubertal heifer is more sensitive to exogenous GnRH in terms of acute FSH release would account for this disparity between the species (McLeod, Haresign, Peters \& Lamming, 1984). In addition, the absence of consistent 60 - and 40.5min cycles in FSH in those animals in which 120 -min cycles were detected can be explained by a widely fluctuating baseline that camouflages any asymmetry in FSH episodes.

When comparison is made of the episode frequencies detected by the three methods of analysis used, the limitations of each of these techniques become apparent. Even when attempts are made to introduce a degree of objectivity by strict adherence to rigid criteria defining episodes, the subjective nature of visual assessment of episode frequency persists. The bias imposed on the results by the choice of definition is clearly demonstrated in Text-fig. 4. Cycle detection attempts to overcome these problems, and is effective when used within its defined constraints. However, this method of analysis is appropriate only when all episodes are of equal amplitude. In most of the animals treated with injections of GnRH at 2-h intervals, cycle detection underestimated LH episode frequency. Similarly, time series analysis is an effective, objective method of assessing episodic secretion when it is used in appropriate situations. It is specifically designed to detect regularly recurring events, and its efficacy is demonstrated in the detection of those $\mathrm{LH}$ episodes that are visually obvious in animals injected with GnRH. In addition, it is able to identify several overlying cycles, a situation in which simple inspection of hormone profiles is often useless. However, as has been illustrated in these analyses, when non-sinusoidal wave patterns are involved, real cycles in hormone secretion may generate false cycles which are merely their harmonics. On the other hand, analysis of FSH profiles in prepubertal heifers has demonstrated that time series analysis is capable of detecting regularly recurring cycles in secretion which other methods of analysis fail to identify. It is possible that these too are artefacts, but the ability of this method of analysis to detect artificially-driven, visually obvious cycles in LH secretion in the same animals would suggest that the 2-h FSH cycles are real.

To summarize, these methods of assessing episodic secretion of gonadotrophic hormones are severely limited in many biological situations by their requirements for a universally acceptable definition of an episode, for episodes of equal amplitude or for episodes occurring at regular intervals. Nevertheless, there are specific situations when each of these methods can contribute to the interpretation of endocrine profiles. When assay variability (noise) is low and episodes occur infrequently, the application of predetermined criteria to hormone profiles to identify individual episodes provides reliable information of episode frequency and amplitude. As noise levels increase and as episodes overlap, this method becomes increasingly less effective. In this situation, cycle detection can analyse data of any shape and with regular or irregular rhythms, to produce objective estimates of mean episode frequency and mean episode amplitude. However, cycle detection does not identify individual episodes and it is inaccurate if the amplitude of successive episodes differs 
by $>50 \%$. Similarly, time series analysis does not identify individual episodes, but if regular rhythms in episodic release are suspected, it will identify the frequency with which they occur even if noise levels are high, recurring cycles overlap and episode amplitude is variable.

We thank Dr D. K. Clifton and Dr R. A. Steiner, University of Washington, U.S.A., for the cycle detection programme; the A.F.R.C. and Hoechst Pharmaceuticals for financial support; Hoechst Pharmaceuticals for supplies of GnRH; and N.I.H., Bethesda, U.S.A., for the standard LH and FSH.

\section{References}

Almeida, O.F.X. \& Lincoln, G.A. (1982) Photoperiodic regulation of reproductive activity in the ram: evidence for the involvement of circadian rhythms in melatonin and prolactin secretion. Biol. Reprod. 27, 1062-1075.

Baird, D.T. (1978) Pulsatile secretion of LH and ovarian estradiol during the follicular phase of the sheep estrous cycle. Biol. Reprod. 18, 359-364.

Beck, T.W. \& Convey, E.M. (1976) Serum LH in heifers after ovariectomy. J. Anim. Sci. 43, 274-275, Abstr.

Butler, W.R., Malven, P.V., Willet, L.B. \& Bolt, D.J. (1972) Patterns of pituitary release and cranial output of LH and prolactin in ovariectomized ewes. Endocrinology 91, 793-801.

Chatfield, C. (1980) Spectral analysis. In The Analysis of Time Series: An Introduction, pp. 127-168. Chapman \& Hall, London.

Clarke, I.J. \& Cummins, J.T. (1982) The temporal relationship between gonadotropin releasing hormone (GnRH) and luteinizing hormone (LH) secretion in ovariectomized ewes. Endocrinology 111, 1737-1739.

Clifton, D.K. \& Steiner, R. A. (1983) Cycle Detection : A technique for estimating the frequency and amplitude of episodic fluctuations in blood hormone and substrate concentrations. Endocrinology 112, 10571064.

Dierschke, D.J., Battacharya, A.N., Atkinson, L.E. \& Knobil, E. (1970) Hypophysial responses to continuous and intermittent delivery of hypothalamic gonadotrophin-releasing hormone. Science, N.Y. 202, 631-633.

Ellis, B.W., Randall, N.J., Becket, A.J. \& Dudley, H.A.F. (1978) Continuous blood sampling and times series analysis in endocrine research. J. Med. Eng.\& Tech. 2, 195-199.

Foster, J.P. \& Crighton, D.B. (1974) Luteinizing hormone (LH) release after single injections of synthetic LH-releasing hormone ( $\mathrm{LH}-\mathrm{RH})$ in the ewe at three different reproductive stages and comparison with natural LH release at oestrus. Theriogenology 2, 87100.

Foster, D.L., Jaffe, B.L. \& Niswender, G.D. (1975) Sequential patterns of circulating $\mathrm{LH}$ and FSH in female sheep during the early postnatal period: effect of gonadectomy. Endocrinology 90, 158-162.

Gay, V.L. \& Sheth, N. (1972) Evidence for periodic release of $\mathrm{LH}$ in castrated male and female rats. Endocrinology 90, 158-162.

Goodman, R.L. \& Karsch, F.J. (1980) Pulsatile secretion of luteinizing hormone: differential suppression by ovarian steroids. Endocrinology 107, 1286-1290.

Howles, C.M., Craigon, J. \& Haynes, N.B. (1982) Longterm rhythms of testicular volume and plasma prolactin concentrations in rams reared for 3 years in constant photoperiod. J. Reprod. Fert. 65, 439-446.

Jenkins, C.M. \& Watts, D.G. (1968) The spectrum. In Spectral Analysis and Its Applications, pp. 209-257. Eds G. M. Jenkins \& E. Parzen. Holden-Day, San Francisco.

Lamming, G.E., Wathes, D.C. \& Peters, A.R. (1981) Endocrine patterns of the post-partum cow. $J$. Reprod. Fert., Suppl. 30, 155-170.

Levine, J.E., Pau, K.F., Ramirez, V.D. \& Jackson, G.L. (1982) Simultaneous measurement of luteinizing hormone-releasing hormone and luteinizing hormone release in unanesthetized, ovariectomized sheep. Endocrinology 111, 1449-1455.

McLeod, B.J. \& Haresign, W. (1984) Evidence that progesterone may influence subsequent luteal function in the ewe by modulating preovulatory follicle development. J. Reprod. Fert. 71, 381-386.

McLeod, B.J., Haresign, W. \& Lamming, G.E. (1982a) The induction of ovulation and luteal function in seasonally anoestrous ewes treated with small-dose multiple injections of Gn-RH. J. Reprod. Fert. 65, 215-221.

McLeod, B.J., Haresign, W. \& Lamming, G.E. (1982b) Response of seasonally anoestrous ewes to small-dose multiple injections of Gn-RH with and without progesterone pretreatment. J. Reprod. Fert. 65, 223230.

McLeod, B.J., Haresign, w. \& Lamming, G.E. (1983) Induction of ovulation in seasonally anoestrous ewes by continuous infusion of low doses of Gn-RH. $J$. Reprod. Fert. 68, 489-495.

McLeod, B.J., Haresign, W., Peters, A.R. \& Lamming, G.E. (1984) Plasma LH and FSH concentrations in prepubertal beef heifers before and in response to repeated injections of low doses of Gn-RH. J. Reprod. Fert. 70, 137-144.

McLeod, B.J., Peters, A.R., Haresign, W. \& Lamming, G.E. (1985) Plasma $\mathrm{LH}$ and FSH responses and ovarian activity in prepubertal heifers treated with repeated injections of low doses of GnRH for $72 \mathrm{~h}$. $J$. Reprod. Fert. (in press).

Rahe, C.H., Owens, R.E., Fleeger, J.L., Newton, H.J. \& Harms, P.G. (1980) Pattern of plasma luteinizing hormone in the cyclic cow: dependence upon the period of the cycle. Endocrinology 107, 498-503. 
Rahe, C.H., Fleeger, J.L. \& Harms, P.G. (1982) Evidence for an inherent rhythm in pulsatile $\mathbf{L H}$ release in ovariectomized cows. Theriogenology 18, 573-581.

Roche, J.F., Foster, D.L., Karsch, F.J. \& Dziuk, P.J. (1970) Effect of castration and infusion of melatonin on levels of luteinizing hormone in sera and pituitaries of ewes. Endocrinology 87, 1205-1210.

Ryan, K.D. \& Foster, D.L. (1980) Neuroendocrine mechanisms involved in onset of puberty in the female: concepts derived from the lamb. Fedn Proc. Fedn Am. Socs exp. Biol. 39, 2372-2377.

Schams, D., Schallenberger, E., Gombe, S. \& Karg, H. (1981) Endocrine patterns associated with puberty in male and female cattle. J. Reprod. Fert., Suppl. 30, 103-110.

Vagnucci, A.H., Wong, A.K.C. \& Liu, T.S. (1974) Times series analysis of hormonal patterns in human plasma. Computers \& Biomed. Res. 7, 513-553.

Watters, D.L. \& Schallenberger, E. (1984) Pulsatile secretion of gonadotrophins, ovarian steroids and ovarian oxytocin during the periovulatory phase of the oestrous cycle in the cow. J. Reprod. Fert. 71, 503512.
Walters, D.L., Schams, D. \& Schallenberger, E. (1984) Pulsatile secretion of gonadotrophins, ovarian steroids and ovarian oxytocin during the luteal phase of the oestrous cycle in the cow. J. Reprod. Fert. 71, 479-491.

Webb, R., Lamming, G.E., Haynes, N.B., Hafs, H.D. \& Manns, J.G. (1977) Response of cyclic and postpartum suckled cows to injections of synthetic LHRH. J. Reprod. Fert. 50, 203-210.

Webb, R., Lamming, G.E., Haynes, N.B. \& Foxcroft, G.R. (1980) Plasma progesterone and gonadotrophin concentrations and ovarian activity in post-partum dairy cows. J. Reprod. Fert. 59, 133-143.

Wilson, J.F. \& Morgan, M.A. (1979) Cyclical changes in concentrations of alpha-melanotrophin in the plasma of male and female rats. J. Endocr. 82, 361-366.

Received 5 October 1984 